\title{
Tissue plasminogen activator inhibits NMDA-receptor-mediated increases in calcium levels in cultured hippocampal neurons
}

\author{
Samuel D. Robinson ${ }^{1 \dagger}$, Tet Woo Lee ${ }^{1 \dagger}$, David L. Christie ${ }^{1,2}$ and Nigel P. Birch ${ }^{1,2 \star}$ \\ ${ }^{1}$ School of Biological Sciences and Centre for Brain Research, University of Auckland, Auckland, New Zealand, ${ }^{2}$ Brain \\ Research New Zealand, Rangahau Roro Aotearoa, University of Auckland, Auckland, New Zealand
}

OPEN ACCESS

Edited by:

Robert Lindsay Medcalf, Monash University, Australia

Reviewed by:

Daniela Tropea,

Trinity College Dublin, Ireland

Denis Vivien,

Institut National de la Santé et de la Recherche Médicale,

France

*Correspondence: Nigel P. Birch,

School of Biological Sciences and Centre for Brain Research, University of Auckland, Thomas Building,

3a Symonds Street, Private Bag 92019, Auckland 1142, New Zealand

n.birch@auckland.ac.nz

tPresent address:

Samuel D. Robinson, Department of Biology, University of Utah, Salt Lake City, Utah, USA; Tet Woo Lee, Department of Anatomy, University of Otago, Dunedin, New Zealand

Received: 22 July 2015 Accepted: 23 September 2015 Published: 09 October 2015

Citation:

Robinson SD, Lee TW. Christie DL and Birch NP (2015) Tissue plasminogen activator inhibits NMDA-receptor-mediated increases in calcium levels in cultured hippocampal neurons. Front. Cell. Neurosci. 9:404. doi: 10.3389/fncel.2015.00404
NMDA receptors (NMDARs) play a critical role in neurotransmission, acting as essential mediators of many forms of synaptic plasticity, and also modulating aspects of development, synaptic transmission and cell death. NMDAR-induced responses are dependent on a range of factors including subunit composition and receptor location. Tissue-type plasminogen activator (tPA) is a serine protease that has been reported to interact with NMDARs and modulate NMDAR activity. In this study we report that IPA inhibits NMDAR-mediated changes in intracellular calcium levels in cultures of primary hippocampal neurons stimulated by low $(5 \mu \mathrm{M})$ but not high $(50 \mu \mathrm{M})$ concentrations of NMDA. tPA also inhibited changes in calcium levels stimulated by presynaptic release of glutamate following treatment with bicucculine/4-aminopyridine (4-AP). Inhibition was dependent on the proteolytic activity of tPA but was unaffected by $\alpha_{2}$-antiplasmin, an inhibitor of the tPA substrate plasmin, and receptor-associated protein (RAP), a panligand blocker of the low-density lipoprotein receptor, two proteins previously reported to modulate NMDAR activity. These findings suggest that IPA can modulate changes in intracellular calcium levels in a subset of NMDARs expressed in cultured embryonic hippocampal neurons through a mechanism that involves the proteolytic activity of tPA and synaptic NMDARs.

Keywords: tissue plasminogen activator, NMDA receptor, calcium signaling, hippocampal neurons, synapse

\section{Introduction}

NMDA receptors (NMDARs) play an essential role in the regulation of synaptic strength in the brain (Lau and Zukin, 2007; Traynelis et al., 2010; Paoletti, 2011). These gated cation channels are activated by the excitatory neurotransmitter glutamate and are essential mediators of brain plasticity, impacting synaptic structure and function. NMDA receptor activation leads to rapid alterations in synaptic strength that contribute to long-term potentiation (LTP) and long-term depression as well as longer term changes that are important for maintaining neuronal network function. Stimulation of NMDARs leads to activation of calcium-dependent signaling pathways and changes in expression of plasticity-related genes. It is becoming increasingly clear that these signaling properties are dependent on receptor localization and subunit composition. NMDARs are mobile and move laterally between synaptic and extrasynaptic pools (Lau and Zukin, 2007; Bard and Groc, 2011). Synaptic and extrasynaptic receptors can stimulate different signaling 
pathways resulting in different neuronal responses. These may be mediated by differences in NMDA receptor subunit composition at the different sites, enabling synaptic and extrasynaptic receptors to associate with different signaling molecules (Rao and Finkbeiner, 2007). NMDARs form tetrameric complexes. The subunit composition of these complexes is diverse and plastic, resulting in a large number of receptor subtypes that varies during development and at adult synapses (Paoletti, 2011).

Tissue-type plasminogen activator (tPA) is a member of the serine protease family most well known for its role in vascular thrombolysis where it activates the zymogen plasminogen to form plasmin, which degrades fibrin and remove blood clots (Cesarman-Maus and Hajjar, 2005). tPA has been identified in both the developing and adult nervous system where a number of distinct roles have been proposed (Sappino et al., 1993; Friedman and Seeds, 1994; Ware et al., 1995; Teesalu et al., 2004). tPA is released from neurons following membrane depolarization (Lochner et al., 2006) and regulates LTP and synaptic plasticity. A genetic deficiency of tPA or inhibition of tPA activity leads to a loss of LTP (Frey et al., 1996; Huang et al., 1996; Calabresi et al., 2000) while overexpression of tPA or addition of recombinant tPA leads to prolonged LTP (Baranes et al., 1998; Madani et al., 1999). These and other observations are consistent with roles for tPA in learning and memory (Centonze et al., 2002; Pawlak and Strickland, 2002; Fernández-Monreal et al., 2004b; Benchenane et al., 2007). Several mechanisms may underpin these effects. At the cellular level tPA has been linked to the formation of perforated synapses (Neuhoff et al., 1999) and presynaptic varicosities (Baranes et al., 1998) as well as changes in dendritic spines (Mataga et al., 2004; Pawlak et al., 2005). Mechanistically, the proposed roles for tPA in synaptic plasticity mainly focus on changes in the proteolytic microenvironment impacting the remodeling of extracellular matrix (Wu et al., 2000; Bukhari et al., 2011) and synaptic connectivity, including cleavage of neurotrophins (Pang et al., 2004; Barnes and Thomas, 2008) and neurotransmitter receptors (Samson et al., 2008a; Macrez et al., 2010; Ng et al., 2012).

In this study we have investigated the effects of tPA on NMDA-mediated changes in intracellular calcium levels using a primary embryonic rat hippocampal culture model (Banker and Cowan, 1977). Calcium flux was stimulated directly with varying concentrations of the glutamate receptor agonist NMDA. We also stimulated presynaptic release of glutamate using a $\gamma$-aminobutyric acid $A\left(\mathrm{GABA}_{\mathrm{A}}\right)$ receptor antagonist and potassium channel blocker, 4-aminopyridine (4-AP; Hardingham et al., 2002). Possible roles for plasmin and low density lipoprotein receptor-related protein 1 (LRP-1), an endocytic and signaling receptor that interacts with $\mathrm{tPA}$ (Zhuo et al., 2000) were also examined.

\section{Materials and Methods}

\section{Materials}

Recombinant human tPA (Actilyse ${ }^{\circledR}$ ) was a generous gift from Boehringer Ingelheim (Auckland, New Zealand) or purchased from Biopur (Reinach, Switzerland). For some experiments the excipients in Actilyse ${ }^{\circledR}$ tPA were removed by dialysis against HEPES (Samson et al., 2008b). NMDA, MK-801 and amino-5-phosphonovalerate (APV) were purchased from Sigma Aldrich (Auckland, New Zealand). Nimodipine, bicuculline and 4-AP were purchased from Tocris (MO, USA). 2,7-Bis(4-aminobenzylidene)-cycloheptan-1-one dihydrochloride (tPA-STOP) was purchased from American Diagnostica (Greenwich, CT, USA). Human $\alpha_{2}$-antiplasmin was purchased from MyBioSource (San Diego, CA, USA). Receptor-associated protein (RAP) was produced as a glutathione S-transferase fusion protein and purified by glutathione-affinity chromatography. The glutathione S-transferase tag was removed by thrombin cleavage prior to use. The active site mutant human tPA (S478A) was purchased from Molecular Innovations (MI, USA).

\section{Primary Cell Culture}

The use of animals in this research was approved by the University of Auckland Animal Ethics Committee. Primary hippocampal cultures were prepared from embryonic (E18) Wistar rats as described previously (Borges et al., 2010; Lee et al., 2015). Briefly, dissected hippocampi were dissociated using papain and plated at 20,000 cells/well in clear-bottom, black-walled 96-well amine plates (BD Biosciences, Auckland, New Zealand). Cultures were maintained for 14-17 days in vitro, in Neurobasal medium containing $1 \times$ B27 and $1 \times$ Glutamax (all from Invitrogen, Carlsbad, CA, USA), with half medium changes $24 \mathrm{~h}$ following plating and then at 7 day intervals.

\section{Calcium Assays}

All experiments were performed on cultures maintained for 14-17 days in vitro. Cells were loaded with Fluo4 AM (Life Technologies) according to the manufacturer's instructions. Calcium responses were recorded on an Envision plate reader (Perkin Elmer, MA, USA) using the following settings: excitation filter, FITC $485 \mathrm{~nm}$; emission filter, $520 \mathrm{~nm}$. Each well was recorded individually, with $15 \mathrm{~s}$ of baseline recording, followed by injection of agonist and recording of the response for a further $45 \mathrm{~s}$. Antagonists were added manually $5 \mathrm{~min}$ (tPA) or $15 \mathrm{~min}$ (MK-801, APV, nimodipine, tPA-STOP, $\alpha_{2}$-antiplasmin, RAP), prior to recording. Raw fluorescence data were converted to $\triangle \mathrm{F} / \mathrm{F}_{0}$; where $F_{0}$ is the average fluorescence over the first $15 \mathrm{~s}$ of recording prior to addition of agonist (baseline) and $\Delta \mathrm{F}$ is $\mathrm{F}_{\max }-\mathrm{F}_{0}$.

\section{Statistics}

The area under the curve (AUC) from 0 to $45 \mathrm{~s}$ was determined and used as the dependent variable for all statistical analyses. These data were first transformed using a square root transform to ensure that there was homogeneity of variance and an approximately normal distribution of residuals in the fitted statistical models. The data for all NMDA treatments were analyzed as a complete set. This data set contained 24 individual plates of cells, 121 treatment by plate biological replicates and 351 individual data points. The data for the bicuculline and 4-AP treatments were analyzed separately, 
consisting of 4 plates of cells, 19 treatment by plate replicates and 53 individual data points. Statistical analysis was conducted in R 3.0.2 ( $\mathrm{R}$ Development Core Team, 2013) using linear mixed models of the transformed data. Data were modeled with a one-factor randomized block design containing a fixed effect for treatment and each plate considered a block. This ensured that each experimental unit (block) was a replicate plate of cells, with the technical replicates within a plate functioning as sampling units. As the data contained a nested structure (technical replicates nested within biological replicates) and were not balanced (not all treatments were in all plates, differing number of technical replicates), the mixed models were fitted by restricted maximum likelihood (REML) instead of general linear model/ANOVA (Littell et al., 2002; Lazic, 2010). The statistical model equation (Littell et al., 2002) was $y_{i j k}=\mu+\alpha_{i}+b_{j}+(\alpha b)_{i j}+e_{i j k}$ where $y_{i j k}$ is the transformed AUC measurement for the $k$ th technical replicate for treatment $i$ in plate $j, \mu+\alpha_{i}$ is the mean transformed AUC measurement for treatment $i, b_{j}$ is the random effect associated with plate $j,(\alpha b)_{i j}$ is the plate by treatment random effect (biological replicates) and $e_{i j k}$ is the random error associated with technical replicate $k$ for treatment $i$ in plate $j$. The $\mathrm{R}$ command lmer from the package lme4 (Bates et al., 2013) was used to fit the linear mixed models using the following model specification: transformed_AUC $\sim$ treatment + $(1 \mid$ plate_id $)+(1 \mid$ plate_id:treatment $)$. All statistical tests were planned comparisons between a treatment and the appropriate control and were calculated as contrasts from the fitted models with $p$-values obtained using degrees of freedom determined by the Kenward-Roger method using packages lsmeans (Lenth, 2013) and pbkrtest (Højsgaard, 2014). As these were decided a priori no correction for multiple tests was applied (Ruxton and Beauchamp, 2008). Data are plotted as backtransformed means and SEM.

\section{Results}

\section{tPA Inhibits the Calcium Response of Hippocampal Neurons Activated with Low but not High Concentrations of NMDA}

To study the effect of recombinant tPA on NMDA-mediated calcium flux, intracellular calcium levels were monitored in embryonic hippocampal neurons cultured between 14 and 17 DIV (days in vitro), using a Fluo-4-based calcium assay and a high speed fluorometric plate reader. Treatment with the NMDAR agonist NMDA alone (5-100 $\mu \mathrm{M})$ resulted in a rapid and concentration-dependent increase in intracellular calcium levels (Figures 1A,B). The fluorescent profiles indicated differences in handling between lower $(<10 \mu \mathrm{M})$ and higher $(>10 \mu \mathrm{M})$ concentrations of NMDA. Both responses were characterized by a rapid influx of calcium (the amplitude of which was concentration-dependent) which in the former gradually returned towards baseline, but in the latter plateaued, resulting in sustained calcium levels. In some instances small oscillations were observed at the lower NMDA concentrations. To investigate the effect of tPA on the calcium response,
A

B

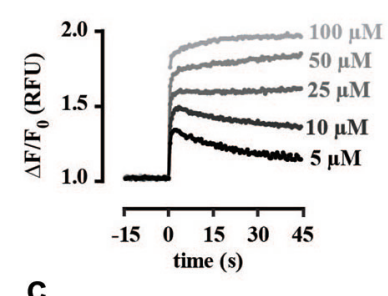

C
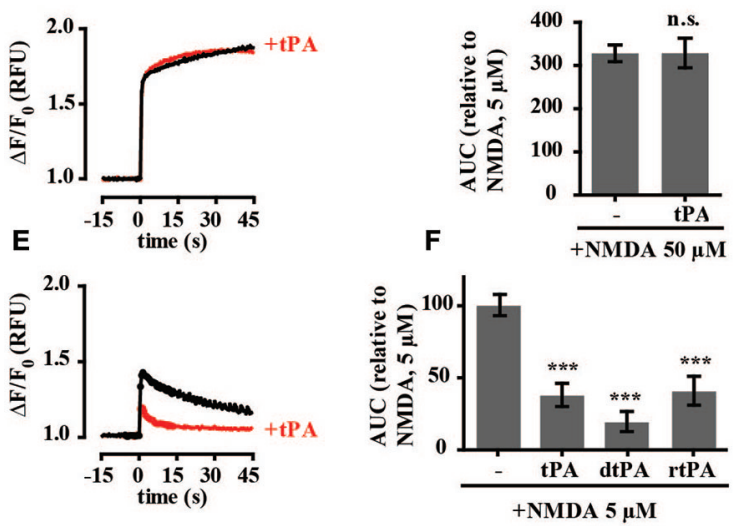

FIGURE 1 | Tissue-type plasminogen activator (tPA) inhibits increases in intracellular calcium in cultured rat hippocampal neurons stimulated with low $(5 \mu \mathrm{M})$ but not high $(50 \mu \mathrm{M})$ concentrations of NMDA.

(A) Baseline Fluo-4 fluorescence was monitored in hippocampal cultures for $15 \mathrm{~s}$ prior to the addition of NMDA, at time $=0$, to final concentrations ranging between 5 and $100 \mu \mathrm{M}$. Fluo- 4 fluorescence was monitored for a further $45 \mathrm{~s}$. Raw fluorescence values were converted to $\Delta F / F_{0}$, where $F_{0}$ is the average fluorescence over the first $15 \mathrm{~s}$ of recording prior to addition of agonist (baseline) and $\Delta \mathrm{F}$ is $\mathrm{F}_{\max }-\mathrm{F}_{0}$. (B) The responses in $\mathrm{A}$ were quantitated by measuring the area under the curve (AUC) and are presented relative to the AUC for $5 \mu \mathrm{M}$ NMDA (100\%). Results are from three independent experiments. Error bar, SEM. (C,D) Hippocampal cultures were preincubated with tPA (40 $\mu \mathrm{g} / \mathrm{ml})$ for $5 \mathrm{~min}$ and Fluo-4 fluorescence monitored before and after addition of NMDA to a final concentration of $50 \mu \mathrm{M}$. Data was collected as in A and quantitated as in B. n.s, not significant. (E) Hippocampal cultures were preincubated with tPA $(40 \mu \mathrm{g} / \mathrm{ml})$ for $5 \mathrm{~min}$ and Fluo-4 fluorescence monitored before and after addition of NMDA to a final concentration of $5 \mu \mathrm{M}$. (F) Quantitation of responses to tPA (Actilyse, sourced from Boehringer Ingelheim), rtPA (rtPA sourced from Biopur) and dtPA (dialysed Actilyse). RFU, Relative Fluorescent Units, ${ }^{* * *} p<0.001$. Error bar, SEM.

Fluo-4-loaded neurons were treated with tPA. Addition of tPA alone $(40 \mu \mathrm{g} / \mathrm{ml})$ did not produce any detectable change in Fluo-4 fluorescence (Supplementary Figure 1) and the calcium response to $50 \mu \mathrm{M}$ NMDA was unaffected by pre-incubation with tPA (Figures 1C,D). However, the calcium response to $5 \mu \mathrm{M}$ NMDA was significantly reduced to $38 \pm 8 \%$ of control (Figures 1E,F). The tPA used in these experiments (Actilyse ${ }^{\circledR}$ ) contains a number of excipients, including L-arginine, which has been suggested to be toxic to neurons (Oh et al., 2005; Samson et al., 2008b). To examine for any effects of the excipients in the Actilyse ${ }^{\circledR}$ tPA on the calcium response we repeated the experiments with a dialysed preparation of Actilyse ${ }^{\circledR}$ tPA (dtPA) and a second commercial recombinant tPA, Biopur tPA, which does not contain excipients. Both produced 
similar inhibition of the $5 \mu \mathrm{M}$ NMDA-mediated calcium response (Figure 1F), supporting the designation of tPA as the active agent. For all subsequent experiments Actilyse ${ }^{\circledR}$ tPA, which will be referred to from now simply as tPA, was used.

\section{tPA Modulates Trans-Synaptic Stimulation of NMDA Receptors}

To investigate the NMDAR responses in more detail we assessed the effects of glutamate and calcium channel antagonists on tPA-sensitive calcium flux. The selective competitive NMDAR antagonist APV $(50 \mu \mathrm{M})$ and the use-dependent NMDAR open channel blocker MK-801 $(10 \mu \mathrm{M})$ both significantly inhibited the calcium response of neurons treated with $50 \mu \mathrm{M}$ NMDA while the L-type voltage-gated calcium channel blocker nimodipine $(10 \mu \mathrm{M})$ had no significant effect on calcium levels (Figures 2A-D). The calcium response of hippocampal neurons to $5 \mu \mathrm{M}$ NMDA was also blocked by APV and MK801. However, in contrast to stimulation with $50 \mu \mathrm{M}$ NMDA, nimodipine also inhibited the response (Figures $2 \mathrm{E}-\mathbf{H}$ ). These results are consistent with previously published data (Jensen and Wang, 1996; Soriano et al., 2006) and support trans-synaptic activation of the postsynaptic cell by glutamate at $5 \mu \mathrm{M}$ NMDA, and direct stimulation of postsynaptic NMDARs at $50 \mu \mathrm{M}$ NMDA. We further investigated an effect of tPA on the calcium response stimulated by presynaptic release of glutamate using the $\mathrm{GABA}_{\mathrm{A}}$ receptor antagonist bicuculline $(50 \mu \mathrm{M})$ and the potassium channel blocker 4-AP $(250 \mu \mathrm{M}$; Hardingham et al., 2001b). Treatment resulted in synchronous spontaneous calcium oscillations suggestive of synaptic coupling between neurons (Figures 3A-C). These oscillations were markedly reduced by $\mathrm{MK}-801$ and nimodipine (Figures $\mathbf{3 A - C , D ) . ~ I m p o r t a n t l y , ~}$ the calcium oscillations were also markedly inhibited by tPA (Figure 3D).

\section{The Proteolytic Activity of tPA is Required for its Inhibitory Effect on NMDA-Mediated Changes in Intracellular Calcium Levels}

As proteolytic and non-proteolytic mechanisms have been reported to modulate NMDA-mediated calcium levels, we tested the effects of tPA-STOP, a reversible competitive inhibitor of trypsin-like serine proteases, as well as an enzymatically inactive tPA mutant. Unexpectedly, preincubation of cultures with $1 \mu \mathrm{M}$ tPA-STOP alone almost completely inhibited intracellular calcium changes activated by $5 \mu \mathrm{M}$ NMDA (Supplementary Figure 2). This result suggested an off-target effect of tPA-STOP and so it was not used in any further experiments. In a second approach we tested the effect of an enzymatically-inactive tPA mutant, with the active site $\operatorname{Ser}_{478}$ residue mutated to alanine. In contrast to $\mathrm{tPA}$, the enzymatically-inactive $\mathrm{tPA}_{\mathrm{S} 478 \mathrm{~A}}$ had no effect on $5 \mu \mathrm{M}$ NMDA-mediated changes in calcium levels (Figures 4A,B).

\section{Inhibition of NMDA-Induced Calcium Influx by tPA is Independent of Plasmin and LRP-1}

To investigate if tPA's effects on intracellular calcium levels involved tPA-mediated activation of plasmin, cultures were preincubated with $\alpha_{2}$-antiplasmin. $\alpha_{2}$-antiplasmin $(140 \mathrm{nM})$ alone did not affect $5 \mu \mathrm{M}$ NMDA-induced calcium flux and did not block the effect on tPA on $5 \mu \mathrm{M}$ NMDA-induced calcium flux (Figures 5A,B). This suggests that plasmin was not responsible for the observed tPA response. It does not rule out the possibility that tPA may be converting plasminogen to plasmin in our cultures, only that this conversion is not necessary for the observed effect of tPA on $5 \mu \mathrm{M}$ NMDA-induced changes in calcium levels. As tPA has also been proposed to modulate NMDA-mediated calcium flux through interaction with LRP as a complex with a specific tPA inhibitor (Martin et al., 2008; Samson et al., 2008a) experiments were undertaken with the

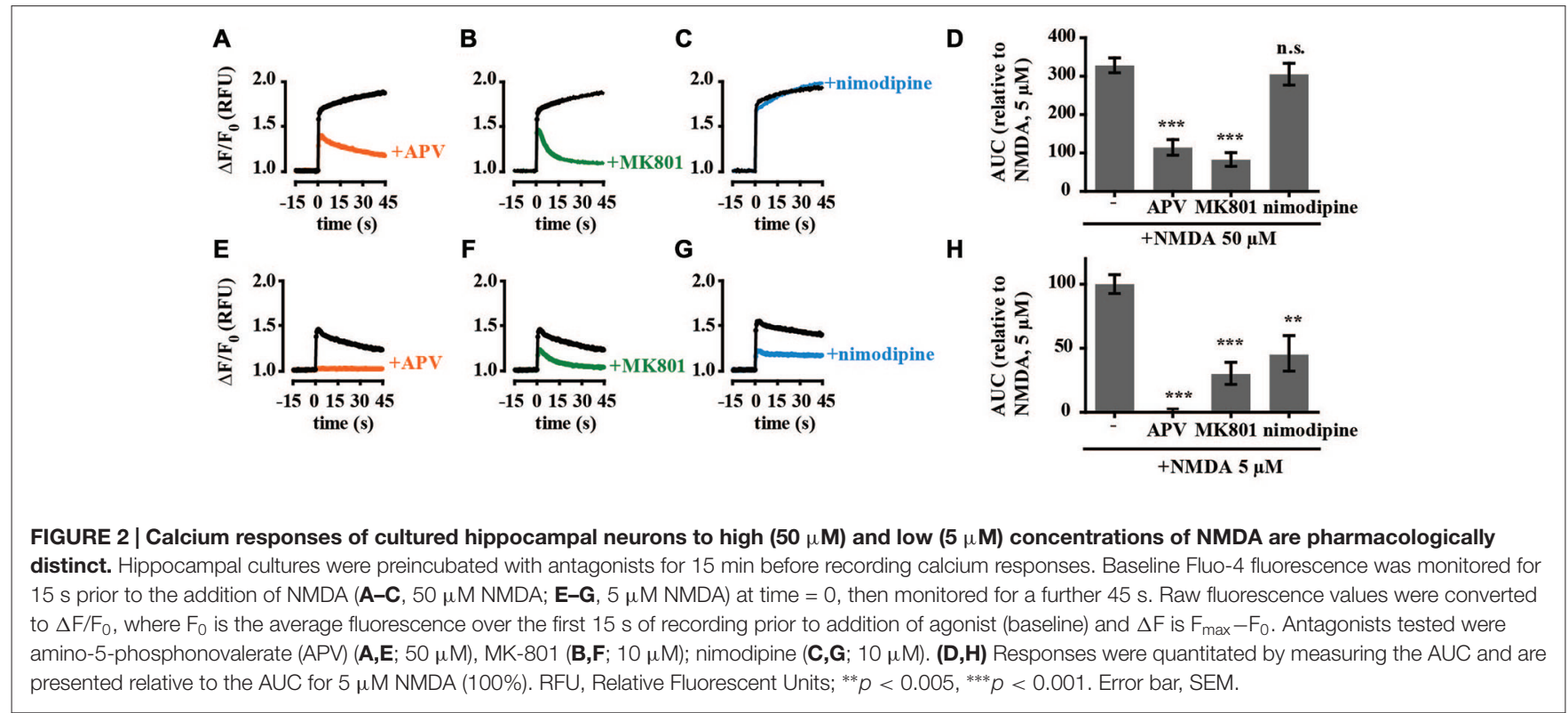


A

B

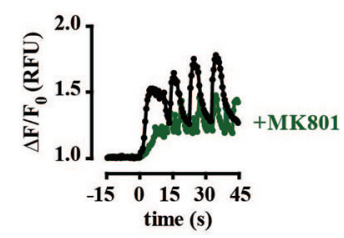

C

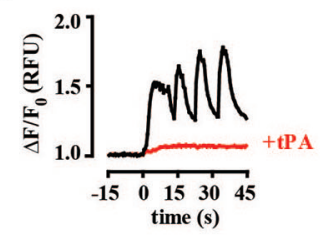

D

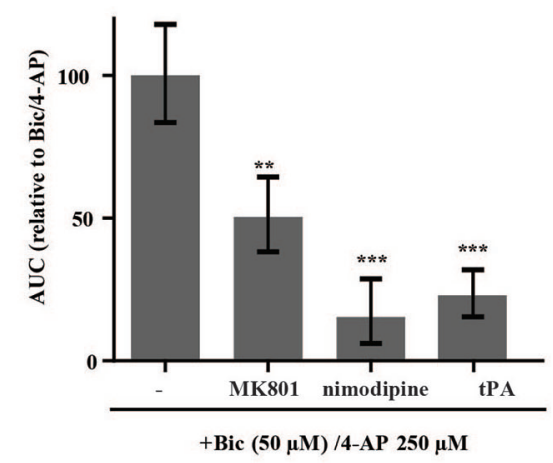

FIGURE 3 | tPA inhibits the calcium response of cultured hippocampal neurons stimulated by presynaptic release of glutamate. Hippocampal cultures were preincubated with antagonists (15 min) or IPA (5 min). Baseline Fluo-4 fluorescence was monitored for $15 \mathrm{~s}$ prior to the addition of bicucculine $(50 \mu \mathrm{M})$ and 4-aminopyridine $(4-\mathrm{AP}, 250 \mu \mathrm{M})$ at time $=0$. Fluorescence was monitored for a further $45 \mathrm{~s}$ and values were converted to $\Delta F / F_{0}$, where $F_{0}$ is the average fluorescence over the first $15 \mathrm{~s}$ of baseline recording. Agents tested were (A,B) nimodipine $(10 \mu \mathrm{M})$, (C) tPA $(40 \mu \mathrm{g} / \mathrm{ml})$. (D) Responses were quantitated by measuring the $\mathrm{AUC}$ and are presented relative to the AUC for $5 \mu \mathrm{M}$ NMDA (100\%). RFU, Relative Fluorescent Units; ${ }^{* *} p<0.005$, ${ }^{* * *} p<0.001$. Error bar, SEM.

competitive LRP-1 receptor antagonist RAP. RAP alone had no effect on NMDA-mediated calcium flux (Figures 5C,D). RAP also failed to block the inhibitory effect of tPA on NMDAmediated calcium flux (Figures 5C,D) suggesting that the tPAmediated inhibition of $5 \mu \mathrm{M}$ NMDA-induced calcium flux does not involve an interaction with LRP-1 or a similar RAP-sensitive receptor.

\section{Discussion}

In this study we have explored the effect of the proteolytic enzyme tPA on NMDA receptor-induced calcium flux in primary cultures of rat hippocampal neurons. Our results reveal that tPA's effects on NMDA-mediated changes in intracellular calcium levels vary with the concentration of NMDA. They support an inhibitory effect of tPA on calcium flux activated

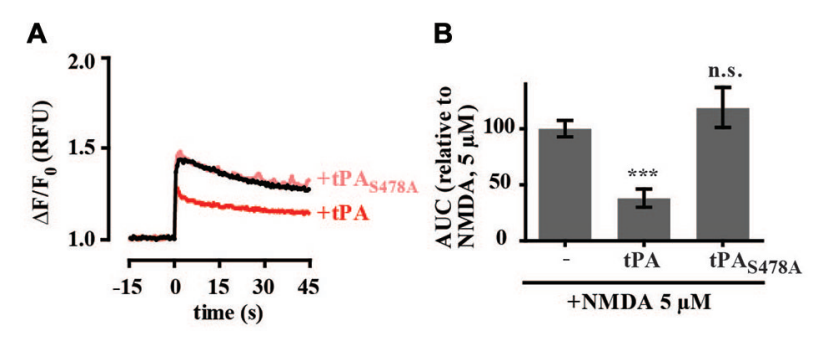

FIGURE 4 | The proteolytic activity of tPA is required for inhibition of NMDA-induced calcium influx. (A) Hippocampal cultures were preincubated with tPA or the enzymatically inactive tPA mutant tPA ${ }_{S 478 A}$ $(40 \mu \mathrm{g} / \mathrm{ml})$ for $5 \mathrm{~min}$. Baseline Fluo-4 fluorescence was monitored for $15 \mathrm{~s}$ prior to the addition of NMDA $(5 \mu \mathrm{M})$, at time $=0$. Fluo- 4 fluorescence was monitored for a further $45 \mathrm{~s}$. Raw fluorescence values were converted to $\Delta F / F_{0}$, where $F_{0}$ is the average fluorescence over the first $15 \mathrm{~s}$ of recording prior to addition of agonist (baseline) and $\Delta F$ is $F_{\max }-F_{0}$. (B) The responses in $A$ were quantitated by measuring the $A \cup C$ and are presented relative to the AUC for $5 \mu \mathrm{M}$ NMDA (100\%). RFU, Relative Fluorescent Units; n.s, not significant; ${ }^{* * *} p<0.001$. Error bar, SEM.

by low concentrations of NMDA or synaptic action potentials, through a mechanism that requires the enzymatic activity of tPA.

We found that pre-treatment of cultured hippocampal neurons with tPA had no effect on intracellular free calcium levels following stimulation with $50 \mu \mathrm{M}$ NMDA. This relatively high concentration of NMDA has been reported to directly activate post-synaptic NMDARs (Bading et al., 1993; Hardingham et al., 2002). Our own results support this view with NMDA-mediated calcium flux activated by $50 \mu \mathrm{M}$ NMDA inhibited by NMDA receptor antagonists but not by an antagonist of voltage-gated calcium channels. In contrast, tPA pre-treatment inhibited NMDA-stimulated calcium flux following activation of cultured hippocampal neurons with $5 \mu \mathrm{M}$ NMDA. While all NMDARs are expected to be activated by this lower concentration of NMDA, the majority of calcium influx in hippocampal neuronal cultures has been attributed to an NMDA-induced increase in neuronal firing. Such action potential-induced intracellular calcium influx is mediated mainly by synaptic NMDARs (Hardingham et al., 2001a, 2002; Soriano et al., 2006). Our results support this view with significant inhibition of the calcium response following antagonism of L-type voltage-gated calcium channels, which have an established role in synaptically-stimulated calcium entry (Jensen and Wang, 1996; Wang and Gruenstein, 1997). We further investigated a role for tPA at synaptic NMDARs by examining its effect on synaptically-evoked bursts of action potentials. Hippocampal cultures typically contain approximately $10 \%$ inhibitory interneurons that tonically inhibit the neuronal network. We treated cultures with the $\mathrm{GABA}_{\mathrm{A}}$ receptor antagonist bicuculline to relieve this inhibition, leading to bursts of action potentials and activity-dependent calcium transients mediated largely by calcium influx through synaptic NMDA receptor (Hardingham et al., 2001b). Co-treatment with 4-AP, a weak potassium-channel blocker led to elevated calcium oscillations with "plateau-type" calcium signal (Hardingham et al., 2002). Pretreatment of these cultures with tPA resulted in 
A
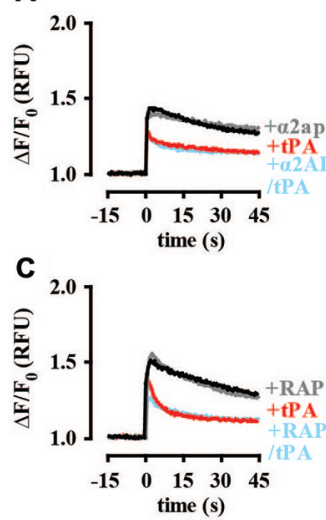

B

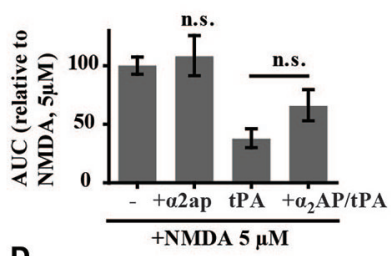

D

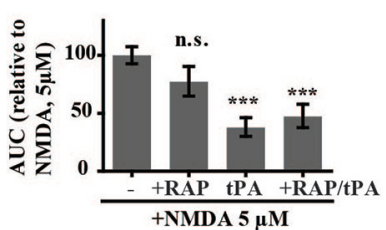

FIGURE 5 | tPA inhibition of NMDA-induced calcium influx is independent of plasmin and lipoprotein receptor-related protein 1 (LRP-1). (A) Hippocampal cultures were preincubated with tPA (40 $\mu \mathrm{g} / \mathrm{ml}$; for $5 \mathrm{~min}$ ) or $\alpha_{2}$-antiplasmin ( $140 \mathrm{nM}$; for $15 \mathrm{~min}$ ) and tPA (for $5 \mathrm{~min}$ ). Baseline Fluo-4 fluorescence was monitored for $15 \mathrm{~s}$ prior to the addition of NMDA $(5 \mu \mathrm{M})$, at time $=0$. Fluo-4 fluorescence was monitored for a further $45 \mathrm{~s}$. Raw fluorescence values were converted to $\Delta F / F_{0}$, where $F_{0}$ is the average fluorescence over the first $15 \mathrm{~s}$ of recording prior to addition of agonist (baseline) and $\Delta F$ is $F_{\max }-F_{0}$. (B) The responses in A were quantitated by measuring the AUC and are presented relative to the AUC for $5 \mu \mathrm{M}$ NMDA (100\%). (C) Hippocampal cultures were preincubated with tPA (40 $\mu \mathrm{g} / \mathrm{ml})$ for 5 min or receptor-associated protein (RAP) ( $500 \mathrm{nM}$; for $15 \mathrm{~min}$ ) and tPA (for $5 \mathrm{~min})$. Baseline Fluo-4 fluorescence was monitored for $15 \mathrm{~s}$ prior to the addition of NMDA $(5 \mu \mathrm{M})$, at time $=0$. Fluo- 4 fluorescence was monitored for a further $45 \mathrm{~s}$. Raw fluorescence values were converted to $\Delta F / F_{0}$, where $F_{0}$ is the average fluorescence over the first $15 \mathrm{~s}$ of recording prior to addition of agonist (baseline) and $\Delta F$ is $F_{\max }-F_{0}$. (D) The responses in $C$ were quantitated by measuring the $A \cup C$ and are presented relative to the $A \cup C$ for $5 \mu \mathrm{M}$ NMDA (100\%). RFU, Relative Fluorescent Units; n.s, not significant; ${ }^{* * *} p<0.001$. Error bar, SEM.

a marked decrease in calcium oscillations, further supporting an inhibitory effect of tPA on synaptic NMDARs.

To the best of our knowledge this is the first study to report an inhibitory effect of tPA on NMDA receptormediated calcium flux in neurons. Several other groups have investigated the effect of tPA on intracellular calcium levels (Nicole et al., 2001; Reddrop et al., 2005; Samson et al., 2008b). However in contrast to our results, these studies reported that IPA potentiated NMDA-mediated calcium levels. While these studies all involved analyses of mouse cortical cultures, either as a mixed population of neurons and glial cells (Nicole et al., 2001) or enriched in neuronal cells (Reddrop et al., 2005; Samson et al., 2008b), our inhibitory responses were seen in rat hippocampal cultures cultured under conditions to enrich for neuronal cells. Glial cells may influence tPA-mediated responses with tPA recently been described as a gliotransmitter (Cassé et al., 2012). Another obvious difference is the concentration of NMDA used across the different experiments. The tPA inhibitory effects we report were seen using $5 \mu \mathrm{M}$ NMDA while the published studies used concentrations ranging between $25 \mu \mathrm{M}$ and $100 \mu \mathrm{M}$. The higher concentrations of NMDA would be expected to result in cellular responses dominated by direct stimulation of NMDARs whereas the inhibitory effects we observe appear to be due to trans-synaptic stimulation of synaptic NMDARs. However, this suggestion alone does not explain why we do not see a potentiation of NMDA-mediated calcium levels at the higher NMDA concentrations. The differential effects of tPA on NMDA-mediated calcium flux could also involve differences in NMDA receptor subunit composition and differences in NMDAR responses reflecting association with regulatory proteins.

Our data support tPA inhibition of NMDA-mediated changes in calcium levels through a proteolytic mechanism. The changes could involve direct effects of tPA on the NMDA receptor to inhibit calcium entry but we cannot exclude changes in intracellular calcium also involving differential release of calcium from intracellular stores. Treatment of cultures with a catalytically inactive tPA mutant did not inhibit NMDAmediated calcium flux. tPA has been proposed to cleave the GluN1 subunit of the NMDA receptor and potentiate NMDAinduced calcium influx (Nicole et al., 2001; Fernández-Monreal et al., 2004a; Reddrop et al., 2005; Benchenane et al., 2007). However, as all NMDARs contain the GluN1 subunit and as cleavage of this subunit potentiates NMDA-activated levels of intracellular calcium in neurons, it seems unlikely that the effects we are seeing are mediated through this subunit. Others have failed to detect cleavage of the GluN1 subunit of the NMDA receptor by tPA (Matys and Strickland, 2003; Kvajo et al., 2004; Liu et al., 2004). There is also evidence that plasmin can modulate NMDA receptor function directly (Samson et al., 2008a) or indirectly (Mannaioni et al., 2008). If plasmin were the functional unit in our assay conditions we would expect to see relief of the tPA-mediated inhibition of intracellular calcium levels when cultures were pre-incubated with the plasmin-specific inhibitor $\alpha_{2}$-antiplasmin. While, no such change was observed (Figures 4A,B), these experiments do not completely exclude a direct role for plasmin. Future experiments should investigate the effects of exogenous plasmin on NMDA-mediated calcium levels.

tPA has also been shown to interact with the NMDA receptor via the low-density LRP1. Several studies have implicated LRP1 as the major tPA receptor in the brain facilitation subsequent downstream signaling (Zhuo et al., 2000) and engagement of the LDLR has been reported to be required for tPA to influence NMDAR function, including potentiation of NMDAmediated calcium influx (Samson et al., 2008a). In these studies the calcium responses of primary cortical cultures to $25 \mu \mathrm{M}$ NMDA were measured before and after a $5 \mathrm{~min}$ perfusion with tPA by video microscopy. tPA was found to enhance NMDA-mediated calcium influx and the effect was blocked by the LDLR pan-ligand blocker RAP. Rather than this response reflecting direct binding of tPA to the LRP receptor, the authors suggest a model where tPA initially interacts with a substrate, which they suggest is protease nexin-1 (PN-1), and a member of the serine protease inhibitor family, and it is this complex that interacts with the LDLR to activate NMDA signaling. We saw no significant effect of RAP alone on NMDAmediated changes in calcium levels. Moreover, in our assay conditions, RAP did not block tPA's inhibitory effect. This may 
suggest that LRP's main influence on NMDAR function, as previously reported, is through an interaction with extrasynaptic NMDARs.

Another potential target of tPA is GluN2D-containing NMDARs. tPA has been proposed to potentiate GluN2Dcontaining NMDA receptor-dependent activation in cortical neurons activated with $50 \mu \mathrm{M}$ NMDA with receptor activation monitored by quantitation of ERK signaling or increased neuronal death (Baron et al., 2010; Jullienne et al., 2011; Parcq et al., 2012). Interestingly, tPA was unable to potentiate NMDAmediated cell death in hippocampal cultures in this study, even though NR2D expression is seen in the CA2 region of the hippocampus. Investigations of tPA's effect on NMDA-mediated changes in intracellular calcium levels in cortical cultures should shed further light on the role of GluN2D-containing NMDARs and is an important area for future study. Another consideration is the molecular form of tPA. tPA is secreted as single-chain tPA but can then undergo cleavage into a two-chain form by plasmin or kallikrein (Rijken et al., 1982; Rajapakse et al., 2005). Parcq et al. (2012) recently reported that single-chain tPA selectively cleaves the NMDA receptor to promote NMDAinduced calcium influx in mouse embryonic cortical cultures with two-chain tPA having no effect. Our experiments used human recombinant $\mathrm{PA}$ (Actilyse) which is $90-95 \%$ single-chain tPA and a recombinant human tPA supplied by Biopur that is also the single-chain form. They further support an important role for single-chain IPA as a modulator of NMDAR responses. Whether two-chain $\mathrm{PAA}$ is inactive in our model remains to be determined.

\section{References}

Bading, H., Ginty, D. D., and Greenberg, M. E. (1993). Regulation of gene expression in hippocampal neurons by distinct calcium signaling pathways. Science 260, 181-186. doi: 10.1126/science.8097060

Banker, G. A., and Cowan, W. M. (1977). Rat hippocampal neurons in dispersed cell culture. Brain Res. 126, 397-442. doi: 10.1016/0006-8993(77)90594-7

Baranes, D., Lederfein, D., Huang, Y. Y., Chen, M., Bailey, C. H., and Kandel, E. R. (1998). Tissue plasminogen activator contributes to the late phase of LTP and to synaptic growth in the hippocampal mossy fiber pathway. Neuron. 21, 813-825. doi: 10.1016/s0896-6273(00)80597-8

Bard, L., and Groc, L. (2011). Glutamate receptor dynamics and protein interaction: lessons from the NMDA receptor. Mol. Cell. Neurosci. 48, 298-307. doi: 10.1016/j.mcn.2011.05.009

Barnes, P., and Thomas, K. L. (2008). Proteolysis of proBDNF is a key regulator in the formation of memory. PLoS One 3:e3248. doi: 10.1371/journal.pone. 0003248

Baron, A., Montagne, A., Cassé, F., Launay, S., Maubert, E., Ali, C., et al. (2010). NR2D-containing NMDA receptors mediate tissue plasminogen activatorpromoted neuronal excitotoxicity. Cell Death Differ. 17, 860-871. doi: 10. 1038/cdd.2009.172

Bates, D. Maechler, M., and Bolker, B., and Walker, S. (2013). lme4: Linear mixedeffects models using Eigen and S4. R package version 1.1-7.

Benchenane, K., Castel, H., Boulouard, M., Bluthé, R., Fernandez-Monreal, M., Roussel, B. D., et al. (2007). Anti-NR1 N-terminal-domain vaccination unmasks the crucial action of tPA on NMDA-receptor-mediated toxicity and spatial memory. J. Cell Sci. 120, 578-585. doi: 10.1242/jcs.03354

Borges, V. M., Lee, T. W., Christie, D. L., and Birch, N. P. (2010). Neuroserpin regulates the density of dendritic protrusions and dendritic spine shape in cultured hippocampal neurons. J. Neurosci. Res. 88, 2610-2617. doi: 10. 1002/jnr.22428
In conclusion, our study has found that tPA can inhibit NMDA receptor-mediated changes in intracellular calcium levels in cultured primary rat embryonic hippocampal neurons when NMDARs are activated with either low concentrations of NMDA or through activation of synaptic NMDARs by blocking $\mathrm{GABA}_{\mathrm{A}}$ receptor function. These effects require tPA to be proteolytically active and appear not to involve plasminogen as a substrate or LRP as part of a receptor-mediated mechanism. Our data provide additional evidence for the involvement of tPA in modulating NMDA receptor function and suggest a further level of complexity to the way that $\mathrm{tPA}$ may influence neuronal physiology and pathology. Further research is needed to determine which NMDA receptor subtypes are affected and how the effects relate to hippocampal synaptic plasticity in vivo (Liu et al., 2004).

\section{Acknowledgments}

We would like to thank Jo Dodd for providing the RAP protein. This research was supported by a grant from the Auckland Medical Research Foundation to NPB and DLC, funding from the UoA to NPB and an Auckland Medical Research Foundation Postdoctoral Fellowship to TWL.

\section{Supplementary Material}

The Supplementary Material for this article can be found online at: http://journal.frontiersin.org/article/10.3389/fncel.2015.00404 /abstract

Bukhari, N., Torres, L., Robinson, J. K., and Tsirka, S. E. (2011). Axonal regrowth after spinal cord injury via chondroitinase and the tissue plasminogen activator (tPA)/plasmin system. J. Neurosci. 31, 14931-14943. doi: 10.1523/jneurosci. 3339-11.2011

Calabresi, P., Napolitano, M., Centonze, D., Marfia, G. A., Gubellini, P., Teule, M. A., et al. (2000). Tissue plasminogen activator controls multiple forms of synaptic plasticity and memory. Eur. J. Neurosci. 12, 1002-1012. doi: 10.1046/j. 1460-9568.2000.00991.x

Cassé, F., Bardou, I., Danglot, L., Briens, A., Montagne, A., Parcq, J., et al. (2012). Glutamate controls tPA recycling by astrocytes, which in turn influences glutamatergic signals. J. Neurosci. 32, 5186-5199. doi: 10.1523/jneurosci.529611.2012

Centonze, D., Napolitano, M., Saulle, E., Gubellini, P., Picconi, B., Martorana, A., et al. (2002). Tissue plasminogen activator is required for corticostriatal longterm potentiation. Eur. J. Neurosci. 16, 713-721. doi: 10.1046/j.1460-9568.2002. 02106.x

Cesarman-Maus, G., and Hajjar, K. A. (2005). Molecular mechanisms of fibrinolysis. Br. J. Haematol. 129, 307-321. doi: 10.1111/j.1365-2141.2005. 05444.x

Fernández-Monreal, M., López-Atalaya, J. P., Benchenane, K., Cacquevel, M., Dulin, F., Le Caer, J.-P., et al. (2004a). Arginine 260 of the amino-terminal domain of NR1 subunit is critical for tissue-type plasminogen activatormediated enhancement of N-methyl-D-aspartate receptor signaling. J. Biol. Chem. 279, 50850-50856. doi: 10.1074/jbc.m407069200

Fernández-Monreal, M., López-Atalaya, J. P., Benchenane, K., Léveillé, F., Cacquevel, M., Plawinski, L., et al. (2004b). Is tissue-type plasminogen activator a neuromodulator? Mol. Cell. Neurosci. 25, 594-601. doi: 10.1016/j.mcn.2003. 11.002

Frey, U., Müller, M., and Kuhl, D. (1996). A different form of long-lasting potentiation revealed in tissue plasminogen activator mutant mice. J. Neurosci. 16, 2057-2063. 
Friedman, G. C., and Seeds, N. W. (1994). Tissue plasminogen activator expression in the embryonic nervous system. Brain Res. Dev. Brain Res. 81, 41-49. doi: 10. 1016/0165-3806(94)90066-3

Hardingham, G. E., Arnold, F. J., and Bading, H. (2001a). A calcium microdomain near NMDA receptors: on switch for ERK-dependent synapse-to-nucleus communication. Nat. Neurosci. 4, 565-566. doi: 10.1038/88380

Hardingham, G. E., Arnold, F. J., and Bading, H. (2001b). Nuclear calcium signaling controls CREB-mediated gene expression triggered by synaptic activity. Nat. Neurosci. 4, 261-267. doi: 10.1038/85109

Hardingham, G. E., Fukunaga, Y., and Bading, H. (2002). Extrasynaptic NMDARs oppose synaptic NMDARs by triggering CREB shut-off and cell death pathways. Nat. Neurosci. 5, 405-414. doi: 10.1038/nn835

Højsgaard, U. (2014). pbkrtest: Parametric bootstrap and Kenward Roger based methods for mixed model comparison.

Huang, Y. Y., Bach, M. E., Lipp, H. P., Zhuo, M., Wolfer, D. P., Hawkins, R. D., et al. (1996). Mice lacking the gene encoding tissue-type plasminogen activator show a selective interference with late-phase long-term potentiation in both Schaffer collateral and mossy fiber pathways. Proc. Natl. Acad. Sci. U S A 93, 8699-8704. doi: 10.1073/pnas.93.16.8699

Jensen, F. E., and Wang, C. (1996). Hypoxia-induced hyperexcitability in vivo and in vitro in the immature hippocampus. Epilepsy Res. 26, 131-140. doi: 10. 1016/s0920-1211(96)00049-6

Jullienne, A., Montagne, A., Orset, C., Lesept, F., Jane, D. E., Monaghan, D. T., et al. (2011). Selective inhibition of GluN2D-containing N-methyl-D-aspartate receptors prevents tissue plasminogen activator-promoted neurotoxicity both in vitro and in vivo. Mol. Neurodegener. 6:68. doi: 10.1186/1750-1326-6-68

Kvajo, M., Albrecht, H., Meins, M., Hengst, U., Troncoso, E., Lefort, S., et al. (2004). Regulation of brain proteolytic activity is necessary for the in vivo function of NMDA receptors. J. Neurosci. 24, 9734-9743. doi: 10. 1523/jneurosci.3306-04.2004

Lau, C. G., and Zukin, R. S. (2007). NMDA receptor trafficking in synaptic plasticity and neuropsychiatric disorders. Nat. Rev. Neurosci. 8, 413-426. doi: $10.1038 / \mathrm{nrn} 2153$

Lazic, S. E. (2010). The problem of pseudoreplication in neuroscientific studies: is it affecting your analysis? BMC Neurosci. 11:5. doi: 10.1186/1471-2202-11-5

Lee, T. W., Tumanov, S., Villas-Bôas, S. G., Montgomery, J. M., and Birch, N. P. (2015). Chemicals eluting from disposable plastic syringes and syringe filters alter neurite growth, axogenesis and the microtubule cytoskeleton in cultured hippocampal neurons. J. Neurochem. 133, 53-65. doi: 10.1111/jnc.13009

Lenth, R. V. (2013). lsmeans: least-squares means. R package version 1.0605.

Littell, R. C., Stroup, W. W., and Freund, R. J. (2002). SAS for Linear Models. 4th Edn. Cary, NC: SAS Institute.

Liu, L., Wong, T. P., Pozza, M. F., Lingenhoehl, K., Wang, Y., Sheng, M., et al. (2004). Role of NMDA receptor subtypes in governing the direction of hippocampal synaptic plasticity. Science 304, 1021-1024. doi: 10.1126/science. 1096615

Lochner, J. E., Honigman, L. S., Grant, W. F., Gessford, S. K., Hansen, A. B., Silverman, M. A., et al. (2006). Activity-dependent release of tissue plasminogen activator from the dendritic spines of hippocampal neurons revealed by live-cell imaging. J. Neurobiol. 66, 564-577. doi: 10.1002/neu.20250

Macrez, R., Bezin, L., Le Mauff, B., Ali, C., and Vivien, D. (2010). Functional occurrence of the interaction of tissue plasminogen activator with the NR1 Subunit of N-methyl-D-aspartate receptors during stroke. Stroke 41, 2950-2955. doi: 10.1161/strokeaha.110.592360

Madani, R., Hulo, S., Toni, N., Madani, H., Steimer, T., Muller, D., et al. (1999). Enhanced hippocampal long-term potentiation and learning by increased neuronal expression of tissue-type plasminogen activator in transgenic mice. EMBO J. 18, 3007-3012. doi: 10.1093/emboj/18.11.3007

Mannaioni, G., Orr, A. G., Hamill, C. E., Yuan, H., Pedone, K. H., McCoy, K. L., et al. (2008). Plasmin potentiates synaptic N-methyl-D-aspartate receptor function in hippocampal neurons through activation of proteaseactivated receptor-1. J. Biol. Chem. 283, 20600-20611. doi: 10.1074/jbc.m8030 15200

Martin, A. M., Kuhlmann, C., Trossbach, S., Jaeger, S., Waldron, E., Roebroek, A., et al. (2008). The functional role of the second NPXY motif of the LRP1 beta-chain in tissue-type plasminogen activator-mediated activation of N-methyl-D-aspartate receptors. J. Biol. Chem. 283, 12004-12013. doi: 10. 1074/jbc.m707607200
Mataga, N., Mizuguchi, Y., and Hensch, T. (2004). Experience-dependent pruning of dendritic spines in visual cortex by tissue plasminogen activator. Neuron. 44, 1031-1041. doi: 10.1016/j.neuron.2004.11.028

Matys, T., and Strickland, S. (2003). Tissue plasminogen activator and NMDA receptor cleavage. Nat. Med. 9, 371-373. doi: 10.1038/nm0403-371

Neuhoff, H., Roeper, J., and Schweizer, M. (1999). Activity-dependent formation of perforated synapses in cultured hippocampal neurons. Eur. J. Neurosci. 11, 4241-4250. doi: 10.1046/j.1460-9568.1999.00856.x

Ng, K.-S., Leung, H.-W., Wong, P. T.-H., and Low, C.-M. (2012). Cleavage of NR2B N-terminus of N-methyl-D-aspartate (NMDA) receptor by tissue plasminogen activator: identification of the cleavage site and characterization of ifenprodil and glycine affinities on truncated NMDA receptor. J. Biol. Chem. 287, 25520- 25529. doi: 10.1074/jbc.m112.374397

Nicole, O., Docagne, F., Ali, C., Margaill, I., Carmeliet, P., MacKenzie, E. T., et al. (2001). The proteolytic activity of tissue-plasminogen activator enhances NMDA receptor-mediated signaling. Nat. Med. 7, 59-64. doi: 10.1038/83358

Oh, H.-S., Kwon, O. W., Chung, I., Lee, S. C., Koh, H. J., Lee, S.-H., et al. (2005). Retinal toxicity of commercial tissue plasminogen activator is mediated by the induction of nitric oxide in the mouse retinal primary cells. Curr. Eye Res. 30, 291-297. doi: 10.1080/02713680590923267

Pang, P. T., Teng, H. K., Zaitsev, E., Woo, N. T., Sakata, K., Zhen, S., et al. (2004). Cleavage of proBDNF by tPA/plasmin is essential for longterm hippocampal plasticity. Science 306, 487-491. doi: 10.1126/science. 1100135

Paoletti, P. (2011). Molecular basis of NMDA receptor functional diversity. Eur. J. Neurosci. 33, 1351-1365. doi: 10.1111/j.1460-9568.2011.07628.x

Parcq, J., Bertrand, T., Montagne, A., Baron, A. F., Macrez, R., Billard, J. M., et al. (2012). Unveiling an exceptional zymogen: the single-chain form of tPA is a selective activator of NMDA receptor-dependent signaling and neurotoxicity. Cell Death Differ. 19, 1983-1991. doi: 10.1038/cdd.2012.86

Pawlak, R., Rao, B. S. S., Melchor, J. P., Chattarji, S., McEwen, B., and Strickland, S. (2005). Tissue plasminogen activator and plasminogen mediate stress-induced decline of neuronal and cognitive functions in the mouse hippocampus. Proc. Natl. Acad. Sci. U S A 102, 18201-18206. doi: 10.1073/pnas.0509232102

Pawlak, R., and Strickland, S. (2002). Tissue plasminogen activator and seizures: a clot-buster's secret life. J. Clin. Invest. 109, 1529-1531. doi: 10 $1172 /$ jci200215961

Rajapakse, S., Ogiwara, K., Takano, N., Moriyama, A., and Takahashi, T. (2005). Biochemical characterization of human kallikrein 8 and its possible involvement in the degradation of extracellular matrix proteins. FEBS Lett. 579, 6879-6884. doi: 10.1016/j.febslet.2005.11.039

Rao, V. R., and Finkbeiner, S. (2007). NMDA and AMPA receptors: old channels, new tricks. Trends Neurosci. 30, 284-291. doi: 10.1016/j.tins.2007.03.012

R Development Core Team. (2013). R: a language and environment for statistical computing. R. Foundation. for Statistical Computing, Vienna, Austria. Retrieved 4 January, 2014.

Reddrop, C., Moldrich, R. X., Beart, P. M., Farso, M., Liberatore, G. T., Howells, D. W., et al. (2005). Vampire bat salivary plasminogen activator (desmoteplase) inhibits tissue-type plasminogen activator-induced potentiation of excitotoxic injury. Stroke 36, 1241-1246. doi: 10.1161/01.str.0000166050.84056.48

Rijken, D. C., Hoylaerts, M., and Collen, D. (1982). Fibrinolytic properties of onechain and two-chain human extrinsic (tissue-type) plasminogen activator. $J$. Biol. Chem. 257, 2920-2925.

Ruxton, G. D., and Beauchamp, G. (2008). Time for some a priori thinking about post hoc testing. Behav. Ecol. 19, 690-693. doi: 10.1093/beheco/arn020

Samson, A. L., Nevin, S. T., Croucher, D., Niego, B., Daniel, P. B., Weiss, T. W., et al. (2008a). Tissue-type plasminogen activator requires a co-receptor to enhance NMDA receptor function. J. Neurochem. 107, 1091-1101. doi: 10. 1111/j.1471-4159.2008.05687.x

Samson, A. L., Nevin, S. T., and Medcalf, R. L. (2008b). Low molecular weight contaminants in commercial preparations of plasmin and t-PA activate neurons. J. Thromb. Haemost. 6, 2218-2220. doi: 10.1111/j.1538-7836.2008. 03174.x

Sappino, A. P., Madani, R., Huarte, J., Belin, D., Kiss, J. Z., Wohlwend, A., et al. (1993). Extracellular proteolysis in the adult murine brain. J. Clin. Invest. 92, 679-685. doi: 10.1172/jci116637

Soriano, F. X., Papadia, S., Hofmann, F., Hardingham, N. R., Bading, H., and Hardingham, G. E. (2006). Preconditioning doses of NMDA promote 
neuroprotection by enhancing neuronal excitability. J. Neurosci. 26, 4509-4518. doi: 10.1523/jneurosci.0455-06.2006

Teesalu, T., Kulla, A., Simisker, A., Sirén, V., Lawrence, D. A., Asser, T., et al. (2004). Tissue plasminogen activator and neuroserpin are widely expressed in the human central nervous system. Thromb. Haemost. 92, 358-368. doi: 10. 1160/th02-12-0310

Traynelis, S. F., Wollmuth, L. P., McBain, C. J., Menniti, F. S., Vance, K. M., Ogden, K. K., et al. (2010). Glutamate receptor ion channels: structure, regulation and function. Pharmacol. Rev. 62, 405-496. doi: 10.1124/pr.109.002451

Wang, X., and Gruenstein, E. I. (1997). Mechanism of synchronized Ca2+ oscillations in cortical neurons. Brain Res. 767, 239-249. doi: 10.1016/s00068993(97)00585-4

Ware, J. H., Dibenedetto, A. J., and Pittman, R. N. (1995). Localization of tissue plasminogen activator mRNA in adult rat brain. Brain Res. Bull. 37, 275-281. doi: 10.1016/0361-9230(95)00008-3

Wu, Y. P., Siao, C. J., Lu, W., Sung, T. C., Frohman, M. A., Milev, P., et al. (2000). The tissue plasminogen activator (tPA)/plasmin extracellular proteolytic system regulates seizure-induced hippocampal mossy fiber outgrowth through a proteoglycan substrate. J. Cell Biol. 148, 1295-1304. doi: 10.1083/jcb. 148.6.1295

Zhuo, M., Holtzman, D. M., Li, Y., Osaka, H., DeMaro, J., Jacquin, M., et al. (2000). Role of tissue plasminogen activator receptor LRP in hippocampal long-term potentiation. J. Neurosci. 20, 542-549.

Conflict of Interest Statement: The authors declare that the research was conducted in the absence of any commercial or financial relationships that could be construed as a potential conflict of interest.

Copyright (c) 2015 Robinson, Lee, Christie and Birch. This is an open-access article distributed under the terms of the Creative Commons Attribution License (CC BY). The use, distribution and reproduction in other forums is permitted, provided the original author(s) or licensor are credited and that the original publication in this journal is cited, in accordance with accepted academic practice. No use, distribution or reproduction is permitted which does not comply with these terms. 